\title{
Alpha Tocopherol to Vitamin E Ratio Measurement
}

National Cancer Institute

\section{Source}

National Cancer Institute. Alpha Tocopherol to Vitamin E Ratio Measurement. NCI

Thesaurus. Code C103350.

The determination of the ratio of alpha-tocopherol compared with the total vitamin $\mathrm{E}$ in a sample. The measurement may be expressed as a ratio or percentage. 